\title{
The Resource Mapping Algorithm of Wireless Virtualized Networks for Saving Energy in Ultradense Small Cells
}

\author{
Sai Zou, ${ }^{1,2}$ Fan Yang, ${ }^{1}$ Yulian Tang, ${ }^{1}$ and Lei Xiao ${ }^{2}$ \\ ${ }^{1}$ Department of Communication Engineering, Xiamen University, Xiamen 361005, China \\ ${ }^{2}$ Chongqing College of Electronic Engineering, Chongqing 401331, China \\ Correspondence should be addressed to Yulian Tang; tyl@xmu.edu.cn
}

Received 23 August 2015; Revised 11 November 2015; Accepted 12 November 2015

Academic Editor: Qilian Liang

Copyright (c) 2015 Sai Zou et al. This is an open access article distributed under the Creative Commons Attribution License, which permits unrestricted use, distribution, and reproduction in any medium, provided the original work is properly cited.

\begin{abstract}
As the current network is designed for peak loads, it results in insufficient resource utilization and energy waste. Virtualized technology makes it possible that intelligent energy perception network could be deployed and resource sharing could become an effective energy saving technology. How to make more small cells into sleeping state for energy saving in ultradense small cell system has become a research hot spot. Based on the mapping feature of virtualized network, a new wireless resource mapping algorithm for saving energy in ultradense small cells has been put forward when wireless resource amount is satisfied in every small cell. First of all, the method divides the virtual cells. Again through the alternate updating between small cell mapping and wireless resource allocation, least amount of small cells is used and other small cells turn into sleeping state on the premise of guaranteeing users' QoS. Next, the energy consumption of the wireless access system, wireless resource utilization, and the convergence of the proposed algorithm are analyzed in theory. Finally, the simulation results demonstrate that the algorithm can effectively reduce the system energy consumption and required wireless resource amount under the condition of satisfying users' QoS.
\end{abstract}

\section{Introduction}

With the rise of green network research, the problem of network energy consumption has become a research hot spot [1-3]. A large number of institutions have studied the network energy consumption, for example, the SMART2020 plan proposed by World Climate Group, North American' Green NGI, and British' Green Radio Cores. Most of these projects are applications of communication technology in other fields to reduce global carbon emissions without paying much attention to energy saving technology of mobile communication itself. The existing references point out that the fifth generation $(5 \mathrm{G})$ of mobile communication system is green, which indicates that the research on the wireless network for saving energy is of great significance [4].

$5 \mathrm{G}$ mobile communication system is expected to increase spectrum and energy efficiency at least 10 times and to increase throughput at least 25 times compared to $4 \mathrm{G}$ mobile communication system [5]. According to the Shannon theorem, in order to deal with the pressure of increasing capacity of future wireless network, the traditional solution is to increase the number of base stations and to reduce the size of base station coverage so as to achieve the goal of capacity growth. Obviously, this greatly increases the energy consumption of wireless access networks. $5 \mathrm{G}$ mobile communication system technology is mainly for ultradense network scenarios to manage the deployment of a large number of micro base stations [5]. In response to the capacity increase pressure in future, 5G mobile communication system has become the next battlefield where communications industry giants solve the problem of capacity increase $[4,5]$. 5G mobile communication system technology mainly does not change or only changes partial current network structure and takes advantage of the function of the software to realize the dynamic management of the network. The existing wireless communication network system is mainly designed for area coverage and peak value. That only considers area coverage at the initial stage of deployment, but with the pass of time and the increase of village capacity, it is necessary to divide insufficient capacity of cells, which will make the wireless network topology random and multiply covered $[6,7]$. A huge number of base stations mean high power 
consumption [7]. It has become the direction of the future communication industry and social development to conserve energy, to reduce emissions, and to develop a low-carbon society. Therefore, the research and implementation based on energy conservation as the goal of the new mobile communication network resource control technology are the priority of $5 \mathrm{G}$ mobile communication system.

As the network system is designed for peak load, generally speaking the average load of the network is much lower than the busy load. Based on this, some scholars point out that when there are less active users, they can reduce the number of antenna configurations or sleep base stations directly to achieve the effect of energy saving [8-15]. When the base stations turn into sleeping state, the Quality of Experience of active users inside the cell will become worse. Some scholars put forward the idea that the collaboration of the wireless resource scheduling and the cooperative sleeping ways can be used to achieve energy saving [16-25]. As the base station is isolated and the allocation of wireless resources has been fixed at the beginning of the set, to realize information sharing between different base stations processing is required to establish a centralized controller or control pool of wireless resources, to achieve dynamic management of the small cells. Some scholars put forward the concept of virtualization in cloud platform, which can not only integrate network infrastructure resources, but also manage network effectively through the mapping technology of virtualized network [2632]. How to use virtualized technology through a unified resource scheduling to meet the request of the demand and how to realize the capacity expansion of the whole network while at the same time saving network energy consumption have become the research focuses.

Unlike previous views, on the basis of virtualization, resource mapping algorithm of virtualized network for energy saving in ultradense small cells has been put forward. On the premise of guaranteeing the coverage of the village and the processing capacity of the lower small cells, this algorithm maps resource mapping of baseband pool to the small cells of the approximately minimum number, while the small cells without resource mapping turn into a sleeping state so as to achieve energy saving effects. The contributions of this paper are in four aspects:

(1) Our proposed algorithm first considers the benefitcost ratio of virtualized network mapping and the energy consumption of the system and then puts forward multiobjective decision-making model of virtualized network mapping in the wireless access network. This model can reduce the system energy consumption as much as possible, so as to maximize the mapping benefit-cost ratio approximately.

(2) On the basis of abovementioned model, two-stage mapping algorithm (TSMA) is proposed for the solution. In the first stage, the small cells of approximately minimum number are decided to cover relevant area to make sure that the need of any mobile terminal could be satisfied. In the second stage, wireless resources are mapped to guarantee that users' QoS could be satisfied and wireless resources could be managed by small cells.

(3) Energy consumption of wireless access system, wireless resource utilization, and the convergence of the algorithm are analyzed in theory.

(4) At last, the simulation experiment of the energy consumption, the resource allocation, and the convergence of the algorithm are carried out.

\section{Relevant Work}

In this section, we review some existing power-saving protocols and virtualized technology.

\subsection{Energy Saving Technology of Wireless Access Networks}

2.1.1. Energy Saving Methods by Reducing the Number of Active Stations. The methods of $[8,10,15]$ prove that the sleeping method of base stations can be implemented in engineering. Sleeping model is put forward in [9]. Reference [11] proposes how to dynamically adjust the working status of base stations, depending on the predicted traffic loads. When the base stations have gone into the sleeping state, the communication quality of mobile terminals in sleeping base station will be affected. Reference [12] uses a stochastic geometry model to analyze the sleeping strategies of cellular networks. Reference [13] enlarges or shrinks its cell zooming according to the request of regional cells to achieve energy saving effect. Periodical sleep of the base stations is another method to achieve energy saving effects $[14,15]$. It does monitor the base stations' traffic loads, to judge sleep, but quite a long time is needed to start related equipment to change the base stations from sleeping state into working state, which significantly increases the packet delay.

2.1.2. Discharging Capacity in the Heterogeneous Network. When the mobile terminal is in the area of Wi-Fi or of Access Point (AP), the mobile terminal communicates directly with the relevant signal source, not communicating with base stations, so as to save energy and reduce the traffic load of the base stations [16]. As the hardware of base stations is not sensitive to energy, it does not reduce the energy consumption of the base stations. Various sources aim at different traffic, so users' QoS cannot be guaranteed through access to the nearest AP. Reference [17] chooses different networks to achieve the effect of energy saving according to back haul aware.

2.1.3. To Achieve Energy Saving Effect through the Wireless Resource Configuration. Reference [18] rates energy effects and writes the scores to the corresponding resource block, so that mobile terminal can select the corresponding resource blocks to achieve energy saving effects. Reference [19] analyzes the spectrum effects and energy effects with random geometry. Reference [20] does achieve the effect of energy saving by association of downlink and uplink in C-RAN. Tang et al. have proposed a paradigm for energy efficiency (EE) and spectral efficiency (SE) tradeoff [21]. It is capable 
of exploiting the tradeoff between EE and SE by balancing consumption power and occupied bandwidth. Mobile terminal has multiple access networks. Each time before sending data to the network, channels of mobile terminal should be scanned, and high quality network data transmission should be chosen. Base stations that are not in the process of access will sleep, thus saving energy consumption [22]. Finally through the deployment of mobile base station [23], base stations cooperate [24] or coplan [25] to achieve energy saving effect.

2.2. Method of Virtualized Network Mapping. Virtualized network mapping is the process in which users' virtualized network requests are reasonably mapped to the underlying physical network. The key problem of virtualized mapping is how to efficiently allocate physical network resources to meet the requests and how to maximize the physical network resource utilization on the premise of guaranteeing the physical node functions [26]. At present, most of algorithms of the virtualized network mapping are paid virtualized topology mapping [27]. Virtualized network mapping aiming at energy saving should minimize the physical network energy consumption on the premise of satisfying the current request [28]. Reference [29] proposes reconfigurable virtualized network to minimize energy consumption of the heuristic method. Su et al. put forward virtualized network mapping model of energy consumption and energy perception two-phase algorithm [30]. Wang et al. put forward mixed integer programming model of energy consumption and energy awareness of two-phase mapping algorithm [31]. Reference [32] in cloud data center application of ant colony optimization algorithm tries to solve energy saving virtualized network mapping. As the small cells of wireless access networks are of regional characteristics and the signal of wireless channels is not stable, the above references do research on core network virtualization mapping algorithm for minimizing energy consumption but were not suitable for wireless access networks. Zou et al. put forward resource allocation mechanism based on two-step mapping for saving energy in wireless network virtualization [33]. Reference [33] is the initial results of this work.

\section{System Model}

3.1. Network Topology and Configuration. Area $G$ is a scenario of the ultradense network. In a certain time period $T$, there are small cells and mobile terminals to communicate. $B S=$ $\left\{b s_{1}, \ldots, b s_{m}\right\}$ is a set of small cells. $b s_{i}$ is a small cell. $b s_{i}^{s H}$ and $b s_{i}^{c H}$, respectively, represent maximum coverage area and maximum wireless resource processing capacity of small cell $b s_{i}, i \in\{1, \ldots, m\} . r$ represents the coverage radius of small cell and the length of the diagonal grid. All small cells share a wireless resources pool. The resources pool allocates wireless resources to each small cell in a unified way. Each small cell is connected to the resources pool by cable, as shown in Figure 1.

Assume that the wireless resources to be allocated in the resources pool are abundant, and there is no need to worry about spectrum spatial reuse in the area $G$. The wireless

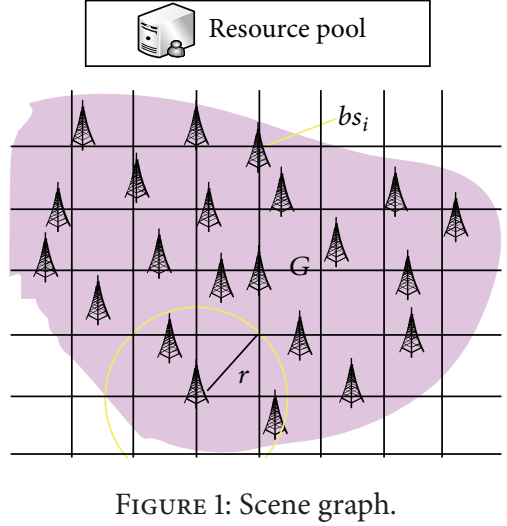

resource amount of dealing with the access information of these mobile terminals is the actual request amount of area $G$. In any place position po $_{i}$ area $G$, there at least exists a small cell which deals with the access of the mobile terminal, as shown

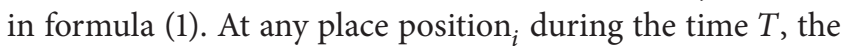
possibility of the emergence of mobile terminal is the same and the number of mobile terminals in each area is different. Consider

$$
\exists \operatorname{position}_{i} \in \sum_{j=1}^{m} b s_{j}^{s H} \quad \forall \text { position }_{i} \in G \text {. }
$$

3.2. Mapping Rules. Mapping aims at making most of small cells into sleeping state and fulfilling the coverage of area $G$ and providing required wireless resources with minimum small cells. On the basis of the rules of virtualized network the whole process is divided into two steps: the obtainment of virtualized requests and mapping of virtualized wireless resources.

Virtualized requests are the actual needed wireless resources of area $G$. The obtaining process is as follows.

The area $G$ is divided into $a \times b$ square grids. The length of diagonal line of the square grid equals the coverage radius $r$ of small cell. $S G=\left\{s g_{1,1}, \ldots, s g_{a, b}\right\}$ stands for the set of grid areas. $s g_{i, j}$ stands for the grid of the $i$ th row and $j$ th line. $s g_{i, j}^{s}$ stands for the area of $s g_{i, j}$ and the constrained relationship is as formula (2), $i \in\{1, \ldots, a\}, j \in\{1, \ldots, b\}, k \in\{1, \ldots, m\}$. Consider

$$
\forall s g_{i, j}^{s}<b s_{k}^{s H}
$$

The needed wireless resource amount of each grid area will be counted and $s g_{i, j}^{r}$ stands for the needed amount of wireless resources.

Virtual cell means the overlapping area of each grid area and coverage area of active small cells, noted by $v_{i} b s_{j} . v_{i}$ stands for the grid area $s g_{g, h}, i=(g-1) \times b+h . b s_{j}$ stands for the $j$ th small cell. $\left[v_{i} b s_{j}\right]^{s}$ and $\left[v_{i} b s_{j}\right]^{r}$, respectively, stand for the coverage area and needed wireless resource amount of virtual cell $v_{i} b s_{j}$. 
As the radio signal of small cells is of multicoverage for area $G$, there exists the constrained condition of formula (3):

$$
\sum_{i=1, j=1}^{a, b} s g_{i, j}^{s} \ll \sum_{k=1}^{m} b s_{k}^{s H}
$$

Virtualized network resource mapping is to allocate the wireless resources of the resources pool to each small cell to satisfy the resource needs of each grid area. It is divided into two stages. First is small cell mapping. With minimum small cells, the whole virtual cells will be covered and it is guaranteed that the requests of mobile terminals from any place in area $G$ can be satisfied. And then it is resource mapping. The wireless resources of the resources pool will be mapped into one or more small cells to make sure that all the requests from each virtual cell could be satisfied and the mapping resource amount of each small cell is not beyond the processing capacity. The process of virtualized network resource mapping is described in mathematical language as shown in formula (4)-(6). Formula (4) says that the obtained wireless resources of each small cell should be less than or equal to the maximum processing capacity and $b s_{i}^{c a}$ stands for the obtained wireless resources of each small cell, $i \in\{1, \ldots, m\}$. Formula (5) says that the obtained wireless resources of each small cell should be more than or equal to the resource request of grid areas. Formula (6) is the completion of formula (4). Consider

$$
\begin{gathered}
b s_{i}^{c a} \leq b s_{i}^{c H}, \\
\sum_{i=1, j=1}^{a, b} s g_{i, j}^{r} \leq \sum_{k=1}^{m} b s_{k}^{c a}, \\
\sum_{i=1}^{m} b s_{i}^{c a} \leq \sum_{i=1}^{m} b s_{i}^{c H} .
\end{gathered}
$$

The small cell and virtual cell have regional characteristics. Any small cell can only handle the information of the virtual cell within the scope of its coverage, so there exist constrained relationship of virtual cell as shown in (7) and a constrained relationship of small cells as shown in (8). $\left[v_{i} b s_{j}\right] B S_{k}$ is a set which is the overlapping area of each small cell and the virtual cell $v_{i} b s_{j}$. $\left[V_{i} B S_{j}\right] b s_{k}$ is a set which is the overlapping area of each virtual cell and the small cell $b s_{k}$. Consider

$$
\begin{aligned}
\text { if } & {\left[v_{i} b s_{j}\right]^{s} \cap b s_{k}^{s H} \neq \phi } \\
\text { then } & {\left[v_{i} b s_{j}\right] B S_{k}=\left[v_{i} b s_{j}\right] B S_{k} \cup b s_{k} } \\
\text { if } & {\left[v_{i} b s_{j}\right]^{s} \cap b s_{k}^{s H} \neq \phi } \\
\text { then } \quad & {\left[V_{i} B S_{j}\right] b s_{k}=\left[v_{i} b s_{j}\right] \cup\left[V_{i} B S_{j}\right] b s_{k} . }
\end{aligned}
$$

3.3. The Underlying Network Energy Consumption. The underlying network energy consumption mainly includes two parts of fixed and dynamic energy consumption of transceiving data. The energy consumption of small cell is shown in

$$
E_{i}= \begin{cases}T p_{b s}^{\text {idle }}+E_{i}^{t+r}, & \text { Active } \\ T p_{b s}^{\text {sleep }}, & \text { Sleep. }\end{cases}
$$

$p_{b s}^{\text {idle }}$ is the energy consumption of the small cell in the idle state. Because the control equipment is not sensitive to energy, there exists the idle state consumption [16]. $E_{i}^{t+r}$ is energy consumption when the small cell $i$ is transceiving data, $i \in\{1, \ldots, m\}$, whose calculation is shown in

$$
E_{i}^{t+r}=\sum_{j=1}^{b s_{i}^{c a}}\left(\mu_{i, t} p_{i, j}^{t}+\mu_{i, r} p_{i, j}^{r}\right) .
$$

$\mu_{i, t}$ is the amount of transmitting data. $p_{i, j}^{t}$ is energy consumption when the $j$ th wireless resource of the $i$ th small cell transmits unit data. $\mu_{i, r}$ is the amount of receiving data. $p_{i, j}^{r}$ is constant and is the energy consumption when the $j$ th wireless resource of the $i$ th small cell receives unit data. $p_{b s}^{\text {sleep }}$ is energy consumption when the small cell $i$ goes into sleeping state. The energy consumption of the whole area is shown in

$$
E_{\text {total }}=\sum_{i=1}^{m} E_{i} \text {. }
$$

3.4. Multiobjective Decision-Making Model for Resource Mapping. Virtualized resource mapping should realize the aim of saving energy, under the premise of maximizing the benefitcost ratio. To maximize the benefit-cost ratio and minimize the energy consumption, multiobjective decision-making model is used to achieve virtualized resource mapping. $\sum_{i=1}^{m}\left[T E_{i}^{\text {idle }}+E_{i}^{t^{\prime}+r^{\prime}}\right]$ is the energy consumption of existing method. $\left|\sum_{i=1, j=1}^{a, b} s g_{i, j}^{r}-\sum_{k=1}^{m} b s_{k}^{c a}\right|$ is the absolute value of the requested wireless resources of virtual cell minus the actual allocation of wireless resources. $\left(\sum_{k=1}^{m}\left[T p_{b s}^{\text {idle }}+E_{k}^{t^{\prime}+r^{\prime}}\right]-\right.$ $\left.E_{\text {total }}\right) /\left|\sum_{i=1, j=1}^{a, b} s g_{i, j}^{r}-\sum_{i=k}^{m} b s_{k}^{c a}\right|$ is the benefit-cost ratio. To sum up, multiobjective decision-making model of virtualized network mapping in wireless access network is shown in

obj $\min \left(E_{\text {total }}\right)$

$$
\max \left(\frac{\sum_{k=1}^{m}\left[T p_{b s}^{\text {idle }}+E_{k}^{t^{\prime}+r^{\prime}}\right]-E_{\text {total }}}{\left|\sum_{i=1, j=1}^{a, b} s g_{i, j}^{r}-\sum_{k=1}^{m} b s_{k}^{c a}\right|}\right)
$$

$$
\begin{array}{ll}
\text { s.t. } & s g_{i, j}^{s}<b s_{k}^{s H} \\
& \exists \text { position }_{i} \in \sum_{k=1}^{m} b s_{k}^{s H} \quad \forall \text { position }_{i} \in G, \\
& \sum_{i=1, j=1}^{a, b} s g_{i, j}^{s} \ll \sum_{k=1}^{m} b s_{k}^{s H} \\
& b s_{k}^{c a} \leq b s_{k}^{c H}
\end{array}
$$




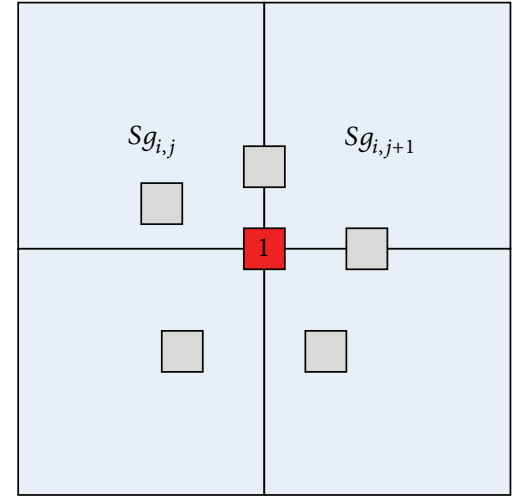

FIGURE 2: The conditions of small cells on vertex of square grid.

$$
\begin{aligned}
& \sum_{i=1, j=1}^{a, b} s g_{i, j}^{r} \leq \sum_{k=1}^{m} b s_{k}^{c a} \\
& \sum_{k=1}^{m} b s_{k}^{c a} \leq \sum_{k=1}^{m} b s_{k}^{c H} \\
& \text { if }\left[v_{x} b s_{y}\right]^{s} \cap b s_{k}^{s H} \neq \phi \\
& \text { then }\left[v_{x} b s_{y}\right] B S_{k}=\left[v_{x} b s_{y}\right] B S_{k} \cup b s_{k} \\
& \text { if }\left[v_{x} b s_{y}\right]^{s} \cap b s_{k}^{s H} \neq \phi \\
& \text { then }\left[V_{x} B S_{y}\right] b s_{k}=\left[v_{x} b s_{y}\right] \cup\left[V_{x} B S_{y}\right] b s_{k} .
\end{aligned}
$$

\section{Two-Stage Mapping Algorithm}

4.1. The Approximate Minimum Cover Set Mapping of Small Cells. To construct Minimum Cover Set (MCS) of a target area is a problem of NP hard [34]; therefore, it has to be counted approximately. Reference [35] presents a distributed approximate algorithm in the sensor networks based on grid partition of Voronoi. Reference [35] can be reference in this paper. Small cell approximate minimum cover mapping algorithm is as follows.

Step 1. If small cell $b s_{k}$ is deployed on one vertex of square grid $g_{i, j}$, then $b s_{k}$ is active and other small cells are sleeping in square grid which is one vertex under $b s_{k}, i \in\{1, \ldots, a\}$, $j \in\{1, \ldots, b\}, k \in\{1, \ldots, m\}$, as shown in Figure 2 .

It is shown that $b s_{1}$ is active from Figure 2.

Step 2. For any $b s_{k}$ deployed in area $G$, assume that $b s_{k}$ is active and deployed on one vertex of $s g_{i, j}$. If there are $b s_{c}$ and $b s_{d}$ which are active in all the $X$-neighboring vertex, and $\left|b s_{c}-b s_{d}\right| \leq \sqrt{2} r, c>k>d$, then $b s_{k}$ is in the sleeping state, $i \in\{1, \ldots, a\}, j \in\{1, \ldots, b\},\{k, c, d\} \subseteq\{1, \ldots, m\}$.

Step 3. For any $b s_{k}$ deployed in area $G$, assume that $b s_{k}$ is active and deployed on one vertex of $s g_{i, j}$. If there are $b s_{e}$ and $b s_{f}$ which are active in all the $Y$-neighboring vertex and

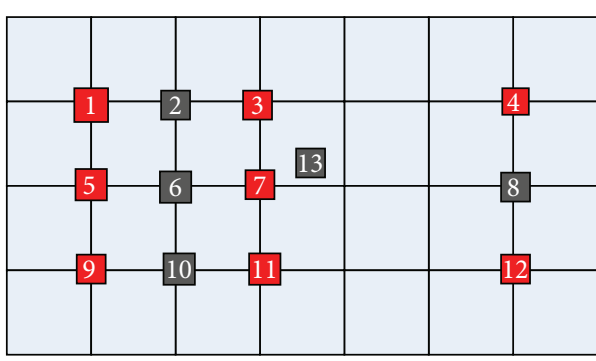

FIgURE 3: The conditions of small cells after Steps 1-3.

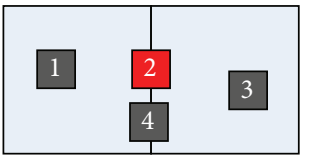

FIGURE 4: The conditions of small cells on edge of square grid.

$\left|b s_{e}-b s_{f}\right| \leq \sqrt{2} r, e>k>f$, and $b s_{k}$ is not $b s_{c}$ or $b s_{d}$ in Step 2 , then $b s_{k}$ is in the sleeping state, $i \in\{1, \ldots, a\}, j \in\{1, \ldots, b\}$, $\{k, c, d, e, f\} \subseteq\{1, \ldots, m\}$.

After the transformation of Steps 2 and 3, we find that $b s_{2}$, $b s_{6}, b s_{8}, b s_{10}$, and $b s_{13}$ are sleeping. The specific conditions are as Figure 3.

Step 4. If small cell $b s_{k}$ is deployed on one edge of the square grid $s g_{i, j}$, assume that there are not active small cells on vertex of the square grid $s g_{i, j}$, and $b s_{k}$ 's number is the smallest on the edge; then $b s_{k}$ is active and other small cells are sleeping in square grid: $i \in\{1, \ldots, a\}, j \in\{1, \ldots, b\}$, and $k \in\{1, \ldots, m\}$, as shown in Figure 4.

It is shown that $b s_{2}$ is active from Figure 4.

Step 5. For any $b s_{k}$ deployed in area $G$, assume that $b s_{k}$ is active and deployed on one edge of $s g_{i, j}$. If there are $b s_{c}$ and $b s_{d}$ which are active in all the $X$-neighboring edge and $\left|b s_{c}-b s_{d}\right| \leq \sqrt{2} r, c>k>d$, then $b s_{k}$ is in the sleeping state, $i \in\{1, \ldots, a\}, j \in\{1, \ldots, b\},\{k, c, d\} \subseteq\{1, \ldots, m\}$.

Step 6. For any $b s_{k}$ deployed in area $G$, assume that $b s_{k}$ is deployed on one line of $s g_{i, j}$ and is active in area $G$. If there are $b s_{e}$ and $b s_{f}$ which are active in all the $Y$-neighboring edge and $\left|b s_{e}-b s_{f}\right| \leq \sqrt{2} r, e>k>f$, and $b s_{k}$ is not $b s_{c}$ or $b s_{d}$ in Step 5 , then $b s_{k}$ is in the sleeping condition, $i \in\{1, \ldots, a\}$, $j \in\{1, \ldots, b\},\{k, c, d, e, f\} \subseteq\{1, \ldots, m\}$.

Step 7. For any $b s_{k}$ deployed in $s g_{i, j}$ of $G$, assume that $s g_{i, j}$ is the grid with no adjacent points and lines and all of $b s_{k}$ 's neighboring $b s$ are not active, if $b s_{k}$ is the most close to the center position and $b s_{k}$ 's number is the smallest in $s g_{i, j}$, then $b s_{k}$ is active and other $b s$ are sleeping in $s g_{i, j}, i \in\{1, \ldots, a\}$, $j \in\{1, \ldots, b\}, k \in\{1, \ldots, m\}$.

Step 8. When there are no $b s$ in $s g_{i, j}$ of area $G, b s$ which get to that $s g_{i, j}$ 's side with distance $r$ are active. If $b s_{c}$ and $b s_{d}$ are 


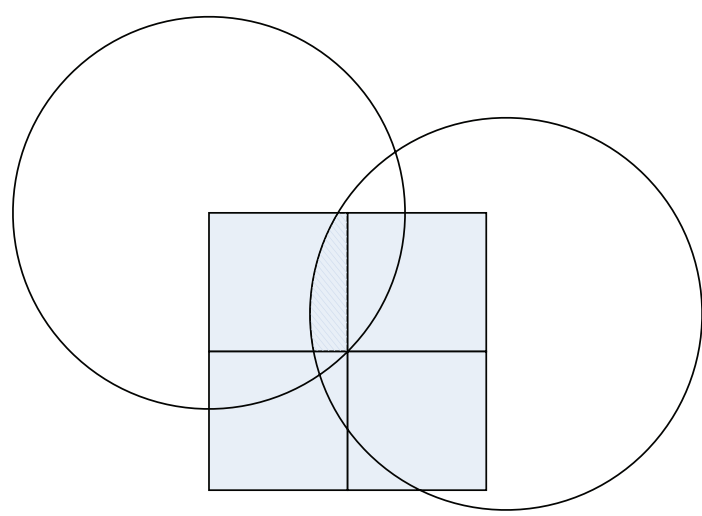

FIgURE 5: Overlapping cover area.

neighboring, and $b s_{c}$ to $s g_{i, j}$ 's distance is greater than or equal to $b s_{d}$ to $s g_{i, j}$ 's distance, then $b s_{c}$ turn to sleep. If $b s_{c}$ and $b s_{d}$ are in grid $s g_{i \pm 1, j \pm 1}$ and $b s_{c}$ to $s g_{i, j}$ 's distance is greater than or equal to $b s_{d}$ to $s g_{i, j}$ 's distance, then $b s_{i}$ is sleeping. If $b s_{c}$ and $b s_{d}$ exist in the same grid $s g_{i \pm 1, j}$ or $s g_{i, j \pm 1}$ or $s g_{i \pm 1, j \pm 1}$ and $b s_{c}$ is a result of Step 7, then $b s_{c}$ is sleeping, $i \in\{1, \ldots, a\}$, $j \in\{1, \ldots, b\},\{k, c, d\} \subseteq\{1, \ldots, m\}$.

Previous Steps 1 to 8 are aiming at assuring that $G$ can be completely covered and that active small cells set $b s^{\text {active }}$ can construe an approximate minimal cover set of area $G$.

\subsection{Resource Mapping}

4.2.1. The Calculation of the Wireless Resource Amount of Virtual Cells. The required wireless resources of virtual cells should be calculated by following steps.

Step 1. Assume that the possibility of the emergency of the mobile terminals in grid area is all the same in any random place, so the required wireless resources of virtual cells are related to the area of virtual cells, as shown in formula (13), $i=(g-1) \times b+h, j \in\{1, \ldots, m\}$. Consider

$$
\left[v_{i} b s_{j}\right]^{s}=s g_{g, h}^{s} \cap b s_{j}^{s} .
$$

Step 2. The area of virtual cell to the area of grid area multiplied by the needed wireless resource amount of grid area is equal to required resource amount of virtual cell as shown in formula (14):

$$
\left[v_{i} b s_{j}\right]^{r}=\frac{\left[v_{i} b s_{j}\right]^{s}}{s g_{g, h}^{s}} s g_{g, h}^{r} .
$$

Step 3. In order to guarantee the completion of the coverage in area $G$ there exists multioverlapping area, as shown in the shadow of Figure 5. In order to reduce the number of allocated wireless resources (to maximize benefit-cost ratio in multiobjective optimization), the requirement of resource in area $G$ whole area will be optimized by $(15),\{k, j\} \subseteq$ $\{1, \ldots, m\}$. One has

$$
\text { set }\left[v_{i} b s_{k}\right]^{r}=0, \quad \forall\left[v_{i} b s_{k}\right]^{s} \in\left[v_{i} b s_{j}\right]^{s}, v_{i} \in s g_{g, h} .
$$

(1) for $\left(b s_{i=1}^{\text {active }} ; b s_{i}^{\text {active }} \in b s^{\text {active }} ; i++\right)$

(2) for $\left(v_{j=1} b s_{i} ; v_{j} b s_{i} \in\left[V_{j} B S_{i}\right] b s_{i} ; j++\right)$

(3) if $\left[\left(b s_{i}^{c a}+\left[v_{j} b s_{i}\right]^{r}\right) \leq b s_{i}^{c H}\right]$ then

(4) $b s_{i}^{c a}=b s_{i}^{c a}+\left[v_{j} b s_{i}\right]^{r}$

(5) else $\left[v_{j} b s_{i}\right]^{r} \rightarrow\left[v_{j} b s_{i}\right]_{\text {free }}^{r}$

Algorithm 1: Wireless resources primary allocation algorithm.

Algorithm 2: Wireless resource allocation algorithm in active small cells.

Step 4. For the convenience of management all virtual cells are ordered from large to small based on virtual cell's size. Combine formula (7), and then the set of virtual cells grouped by grid area is established.

\subsubsection{Resource Allocation}

Step 1. Based on wireless resource quantization and the constrained relationship of small cells shown in formula (8), we rank the wireless resource demand of virtual cells from large to small and get the resource sets of virtual cells corresponding to small cells.

Step 2 (primary allocation of wireless resources). Centered on the small cell, related virtual cells' wireless resource requirements are, respectively, added and are judged according to whether they reach upper limit of small cell wireless resource. If it is not reached, then the wireless resources in pool are mapped into the relevant small cells directly, else waiting for the second allocation. Wireless resources primary allocation algorithm is shown in Algorithm 1.

Step 3. If the wireless resource allocation of active small cells does not reach the upper limit, the wireless resources will be allocated once again among the active small cells for reducing the number of the active small cells, whose process is shown in Algorithm 2.

Step 4. If there is a need to do secondary allocation it means that the current active small cells could not manage the requirements of relevant virtual cells and hence small cells need to be added. That is, more small cells need to be woken from sleeping, as shown in Algorithm 3.

The small cells can be started to undertake the task of wireless resource processing until the wireless resource 
input: wakeupbs $\left(b s_{k}^{\text {sleep }},\left[v_{j} b s_{i}\right]_{\text {free }}^{r}\right)$

(1) $\left\{b s_{k}^{\text {sleep }} \rightarrow b s_{k}^{\text {active }}\right.$

(2) $b s_{k}^{c a}=b s_{k}^{c a}+\left[v_{j} b s_{i}\right]_{\text {free }}^{r}$

(3) $\left[v_{j} b s_{i}\right]_{\text {free }}^{r} \rightarrow\left[v_{j} b s_{i}\right]^{r}$

(4) for $\left(v_{x=1} b s_{k} ; v_{x} b s_{k} \in\left[V_{x} B S_{k}\right] b s_{k} ; x++\right)$

(5) $\quad$ if $\left(\left[v_{x} b s_{k}\right]_{\text {free }}^{r}\right)$ then

(6) $\quad\left\{\right.$ if $\left[\left(b s_{k}^{c a}+\left[v_{x} b s_{k}\right]_{\text {free }}^{r}\right) \leq b s_{k}^{c H}\right]$ then

(7) $\quad b s_{k}^{c a}=b s_{k}^{c a}+\left[v_{x} b s_{k}\right]_{\text {free }}^{r}$

(8) else

(9) $\left\{\left[v_{x} b s_{k}\right]_{\text {free }}^{r}=\left[v_{x} b s_{k}\right]_{\text {free }}^{r}-\left(b s_{k}^{c H}-b s_{k}^{c a}\right)\right.$

(10) $\left.\left.\left.\left.b s_{k}^{c a}=b s_{k}^{c H}\right\}\right\}\right\}\right\}$

Algorithm 3: The algorithm of waking up sleeping small cells.

input: secondaryallocation $\left(\left[v_{j} b s_{i}\right]_{\text {free }}^{r}\right)$

(1) $\left\{\right.$ for $\left(b s_{k=1}^{\text {sleep }} ; b s_{k}^{\text {sleep }} \in\left[v_{j} b s_{i}\right] B S_{k} ; k++\right)$

(2) if $\left(\left[v_{j} b s_{i}\right]^{s} \in\left[v_{j} b s_{k}^{\text {sleep }}\right]^{s}\right)$ then

(3) wakeupbs $\left(b s_{k}^{\text {sleep }},\left[v_{j} b s_{i}\right]_{\text {free }}^{r}\right)$

(4) else

(5) $\quad\left\{\max s=\max \left(\left[v_{j} b s_{i}\right]^{s} \cap\left[v_{j} b s_{*}^{\text {sleep }}\right]^{s}\right)\right.$

(6) wakeupbs $\left(b s_{\max s}^{\text {sleep }}, \max s\right)$

(7) $\quad\left[v_{j} b s_{i}\right]_{\text {free }}^{r}=\left[v_{j} b s_{i}\right]^{s}-\max s$

(8) secondayallocation $\left.\left(\left[v_{j} b s_{i}\right]_{\text {free }}^{r}\right)\right\}$

Algorithm 4: Wireless resources secondary allocation algorithm.

demand of virtual cells has been satisfied or until there are no sleeping small cells, whose realization process algorithm is shown in Algorithm 4.
(1) for $\left(b s_{i=1}^{\text {active }} ; b s_{i}^{\text {active }} \in b s^{\text {active }} ; i++\right)$
(2) if $\left(b s_{i}^{c a}=0\right)$ then
(3) $b s_{i}^{\text {active }} \rightarrow b s_{i}^{\text {sleep }}$

Algorithm 5: Algorithm of turning active small cells into sleeping state.

Step 5. If there are no allocated wireless resources to active small cells, small cells turn into sleeping state, whose realization process is shown in Algorithm 5.

\section{Theory Analysis}

\subsection{Analysis of Energy Consumption}

5.1.1. The Energy Consumption of Transmitting or Receiving Data. As [36] says, the energy consumption of the small cells' transmitting or receiving unit data can be written as formula (16). $p_{l}$ is visual space path loss in the 3GPP-TR-36-814 white paper. $r$ is the distance between mobile terminal and small cell and is calculated by Euclidean Metric, as shown in formula (17). $f_{c}$ is the frequency of small cells to transceiving data. Consider

$$
\begin{aligned}
& p_{l}=22.0 \log _{10}^{d}+28.0+20 \log _{10}^{f_{c}} \\
& d=\sqrt{\left(\text { user }^{x}-b s^{x}\right)^{2}+\left(\text { user }^{y}-b s^{y}\right)^{2}} .
\end{aligned}
$$

The energy consumption of each virtual cell is shown in formula (18), $\mu_{i} \in v_{x}$. The establishment condition of formula (18) is shown in formula (19a), (19b), and (19c).

$$
\begin{aligned}
& {\left[v_{x 1} b s_{y 1}^{\text {active }}\right]_{E}^{r}=\sum_{j=1}^{v_{x 1}}\left(\mu_{i, t} p_{y 1, j}^{t}+\mu_{i, r} p_{y 1, j}^{r}\right)=\sum_{j=1}^{v_{x 1}}\left(\mu_{i, t} p_{l}\right)+\sum_{j=1}^{v_{x 1}}\left(\mu_{i, r} p_{y 1, j}^{r}\right)} \\
& =\sum_{j=1}^{v_{x 1}} \mu_{i, t}\left(22.0 \log _{10}^{d}+28.0+20 \log _{10}^{f_{c}}\right)+\sum_{j=1}^{v_{x 1}}\left(\mu_{i, r} p_{y 1, j}^{r}\right) \\
& \approx \frac{\left[v_{x 1} b s_{y 1}^{\text {active }}\right]^{r}}{v_{x 1}} \sum_{j=1}^{v_{x 1}}\left(22.0 \log _{10}^{d}+28.0+20 \log _{10}^{f_{c}}\right)+\sum_{j=1}^{v_{x 1}}\left(\mu_{i, r} p_{y 1, j}^{r}\right) \\
& =\frac{\left[v_{x 1} b s_{y 1}^{\text {active }}\right]^{r}}{v_{x 1}}\left(\sum_{j=1}^{v_{x 1}}\left(28.0+20 \log _{10}^{f_{c}}\right)+\sum_{j=1}^{v_{x 1}}\left(22.0 \log _{10}^{d}\right)\right)+\sum_{j=1}^{v_{x 1}}\left(\mu_{i, r} p_{y 1, j}^{r}\right)
\end{aligned}
$$

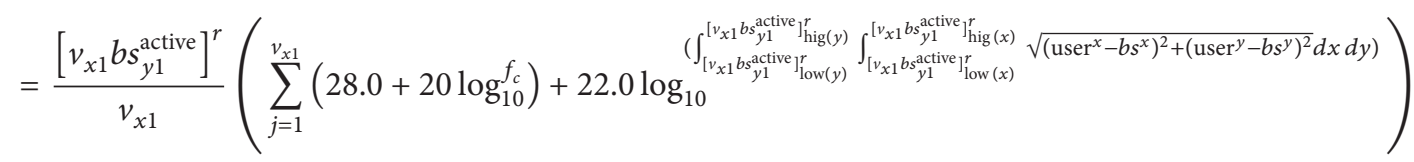

$$
\begin{aligned}
& +\sum_{j=1}^{v_{x 1}}\left(\mu_{i, r} p_{y 1, j}^{r}\right)
\end{aligned}
$$


Formula (19b) stands for the value range in $x$-coordinate of virtual cells $\left[v_{x 1} b s_{y 1}^{\text {active }}\right]$. Formula (19c) is the value range in $y$-coordinate:

$$
\begin{aligned}
& \left(x-\left[b s_{y 1}^{\text {active }}\right]_{x}\right)^{2}+\left(y-\left[b s_{y 1}^{\text {active }}\right]_{y}\right)^{2} \leq r^{2}, \\
& {\left[v_{x 1} b s_{y 1}^{\text {active }}\right]_{\text {low }(x)}^{r} \leq x \leq\left[v_{x 1} b s_{y 1}^{\text {active }}\right]_{\text {hig }(x)}^{r},} \\
& {\left[v_{x 1} b s_{y 1}^{\text {active }}\right]_{\text {low }(y)}^{r} \leq y \leq\left[v_{x 1} b s_{y 1}^{\text {active }}\right]_{\operatorname{hig}(y)}^{r} .}
\end{aligned}
$$

By integrating formula (11) and formula (19a), (19b), and (19c), we can get the total energy consumption of system's receiving and transmitting data as shown in formula (20):

$$
\begin{aligned}
E_{\text {total }}^{r+t} & =\sum_{i=0}^{n} \sum_{k=0}^{m}\left[v_{i} b s_{k}^{\text {active }}\right]_{E}^{r} \\
\approx & \frac{\left[v_{i} b s_{k}^{\text {active }}\right]^{r}}{n}\left(22 \log _{2}^{\left[\int_{G_{\operatorname{low}}(y)}^{G_{\text {hi }}(y)} \int_{G_{\operatorname{low}}(x)}^{G_{\text {hig }}(x)}(r / 2) d x d y\right]^{a}}+c 1\right) \\
& +c 2
\end{aligned}
$$

$G_{\text {low }(x)}, G_{\text {hig }(x)}, G_{\text {low }(y)}$, and $G_{\text {hig }(y)}$ stand for the value range of area $G, c 1=\sum_{j=1}^{v_{x 1}}\left(28.0+20 \log _{10}^{f_{c}}\right)$, and $c 2=$ $\sum_{j=1}^{v_{x 1}}\left(\mu_{i, r} p_{y 1, j}^{r}\right)$.

5.1.2. Total Energy Consumption. Total energy consumption of small cells in area $G$ is the sum of the consumption of sleeping small cells, fundamental energy consumption, and transceiving data of active small cells as shown in formula (21). $N_{\text {active }}$ is the number of active small cells which is the calculation of active $b s$ as shown in formula (22). $N_{\text {sleep }}$ is the number of sleeping small cells which is shown in formula (23):

$$
\begin{aligned}
E_{\text {total }} & =\left(N_{\text {active }} p_{b s}^{\text {idle }}+N_{\text {sleep }} p_{b s}^{\text {sleep }}\right) T+E_{\text {total }}^{r+t}, \\
N_{\text {active }} & =\operatorname{total}\left(b s_{s}^{\text {active }}\right) \\
N_{\text {sleep }} & =N-N_{\text {active }} .
\end{aligned}
$$

5.1.3. Energy Consumption Analysis. It can be seen from formula (23) that total energy consumption consists of two parts: energy consumption of idle state and energy consumption of transceiving data. Reference [35] has proved that the number of active small cells $N_{\text {active }}$ and coverage radius $r$ have an inverse relationship so the energy consumption of small cells is the monotone decreasing function along with the increase of $r$.

It can be seen form formula (20) that $E_{\text {total }}^{r+t}$ is the monotone increasing function along with the increase of $r$. When the sum of transmitting or receiving data is fixed and the coverage density of small cells is fixed, if $r=+\infty$, then $N_{\text {active }}=1$, the energy consumption of small cells is minimum and $E_{\text {total }}^{r+t}$ is maximum. If $r=r^{\prime}$, then $N_{\text {active }}=N$, energy consumption of base equipment is maximum, and
$E_{\text {total }}^{r+t}$ is minimum. It could be seen that $E_{\text {total }}$ is the relevant convex function of $r$. Set $r \in\left[r^{\prime},+\infty\right)$; then there exists minimum value. The results conform to the assumption of this paper which means that two-stage mapping algorithm could get energy saving effects.

5.2. Mapping Cost Minimization and QoS Analysis. To find the solution, the benefit-cost ratio is shown in formula (24):

$$
\begin{aligned}
& \frac{\sum_{k=1}^{m}\left[T E_{k}^{\text {idle }}+E_{k}^{t^{\prime}+r^{\prime}}\right]-E_{\text {total }}}{\left|\sum_{i=1, j=1}^{a, b} s g_{i, j}^{r}-\sum_{k=1}^{m} b s_{k}^{c a}\right|} \\
& =\frac{N E_{k}^{\text {idle }} T+E_{\text {total }}^{t^{\prime}+r^{\prime}}-\left(N_{\text {sleep }} E_{k}^{\text {sleep }}+N_{\text {active }} E_{k}^{\text {idle }}\right) T-E_{\text {total }}^{r+t}}{\left|\sum_{i=1, j=1}^{a, b} s g_{i, j}^{r}-\sum_{x=1}^{V} \sum_{y=1}^{\text {active }}\left[v_{x} b s_{y}^{\text {active }}\right]^{r}\right|} \\
& =\frac{N_{\text {sleep }}\left(E_{k}^{\text {idle }}-E_{k}^{\text {sleep }}\right) T+\left(E_{\text {total }}^{t^{\prime}+r^{\prime}}-E_{\text {total }}^{r+t}\right)}{\left|\sum_{i=1, j=1}^{a, b} s g_{i, j}^{r}-\sum_{x=1}^{v} \sum_{y=1}^{\text {active }}\left[v_{x} b s_{y}^{\text {active }}\right]^{r}\right|} .
\end{aligned}
$$

Along with the increase of the coverage radius of small cells, the value of $E_{\text {total }}^{t^{\prime}+r^{\prime}}-E_{\text {total }}^{r+t}$ can be regarded as the consumed energy when a relay is set at the place of $r-r^{\prime}$; thus $E_{\text {total }}^{t^{\prime}+r^{\prime}}-E_{\text {total }}^{r+t}=\left(\left[v_{i} b s_{k}^{\text {active }}\right]^{r} / n\right)\left(22 \log _{2}\left[\int_{G_{\operatorname{low}}(y)}^{G_{\text {hig }}(y)} \int_{G_{\operatorname{low}(x)}}^{G_{\text {hig }}(x)}(r / 2) d x d y\right]^{a}+\right.$ $c 1)$. And then we could deduce that when the required wireless resources of virtual cells are fixed there exists a coverage radius $r$ of a small cell which helps TSMA save energy. That conforms to the energy consumption analysis in Section 5.1 and also shows that coverage radius $r$ and required wireless resources of virtual cells are one-to-one mapping relationship.

Satisfying QoS means that the amount of wireless resource allocation for any virtual cell should be more than or equal to the amount of wireless resource request. Now we will analyze the wireless resource allocation of each virtual cell. From Section 4.2 it can be seen that each virtual cell and the common area of each small cell comap wireless resources and reach the required amount of the cell, which satisfies QoS.

5.3. Convergence Analysis of the Algorithm. Location of small cells and mobile terminal are random. When the number of mobile terminals is fixed, the number of active small cells is mainly decided by the coverage radius of small cells. The method of value iteration can be used to get the minimum of energy consumption as shown in formula (25):

$$
X_{k+1}=X_{k}+t_{k} p_{k}
$$

$k$ is the iteration times. $p_{k}$ is the moving direction which is regarded as 1 in this paper. The initial point $X_{0}$ is the minimum coverage radius of small cell and $X_{0}=b s_{r=20 \sqrt{2}}$. Set $k=0$, and then step length $t_{k}=(k+1) * b s_{r=20 \sqrt{2}}$. The termination rule is $\left(f\left(X_{k+1}\right)-f\left(X_{k}\right)\right) / f\left(X_{k}\right) \geq 0$ and the specific data could be seen in simulation.

\section{Simulation}

We use the Vienna LTE-A [37] to build the whole simulation platform. We set the related parameters of this simulation 
TABLE 1: Simulation parameters.

\begin{tabular}{lc}
\hline Parameter name & value \\
\hline Length and width of the area $G$ & $100 \mathrm{~m} * 100 \mathrm{~m}$ \\
The number of small cells & 25 \\
The coverage radius of small cell & $r \in[20 \sqrt{2}, 100 \sqrt{2}]$ \\
$\begin{array}{l}\text { Each small cell that can deal with the } \\
\text { number of mobile terminals }\end{array}$ & $\leq 10$ \\
$\begin{array}{l}\text { Each mobile terminal that needs the } \\
\text { number of resource }\end{array}$ & $=1$ \\
Run time & Time of system simulation \\
Idle state current consumption & 15 milliwatts \\
Sleep state current consumption & 0.55 milliwatts \\
\hline
\end{tabular}

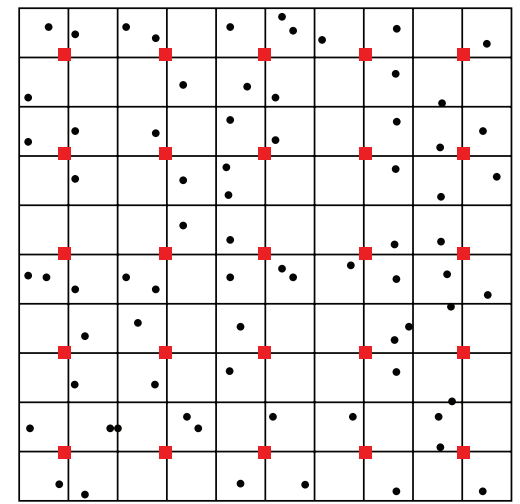

FIGURE 6: The scenario for the discrete uniform distribution of small cells.

experiment in Table 1, according to the model of energy consumption mentioned in [38,39]. Reference [38] is derived from the data of [39].

The simulation is carried out in two scenarios. We first analyze a scene where small cells are discrete uniform distribution in the area $G$ and then test another scene where the small cells are Poisson distribution. Although the discrete uniform distribution can ensure the full coverage of the area $G$, the situation of repetitive wireless resource allocation is impossible to happen because the model is too ideal. Poisson distribution can compensate for these defects but cannot guarantee full coverage in the area $G$ and maybe appear as coverage holes.

6.1. In the Case of the Discrete Uniform Distribution of Small Cells. First, generate 25 small cells of space with the random discrete uniform distribution function. Then generate a mobile terminal in a space by Poisson point process, and the size and the time of data packets transmitted by mobile terminal are equal. Test the energy consumption of different case coverage density, respectively, and test the regional situation and the distribution of the wireless resource request. The result can be shown in Figure 6, where the square represents a small cell and the circle represents a mobile terminal.

Figure 7 shows the situation of the energy consumption with the increase of coverage density, in which coverage

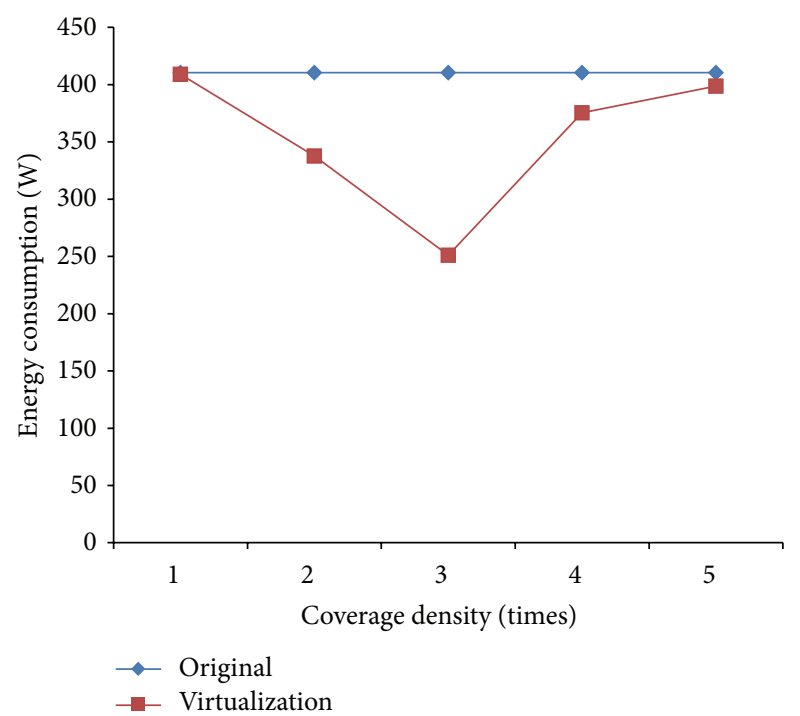

FIGURE 7: The relation of the energy consumption with the coverage density (under discrete uniform distribution).

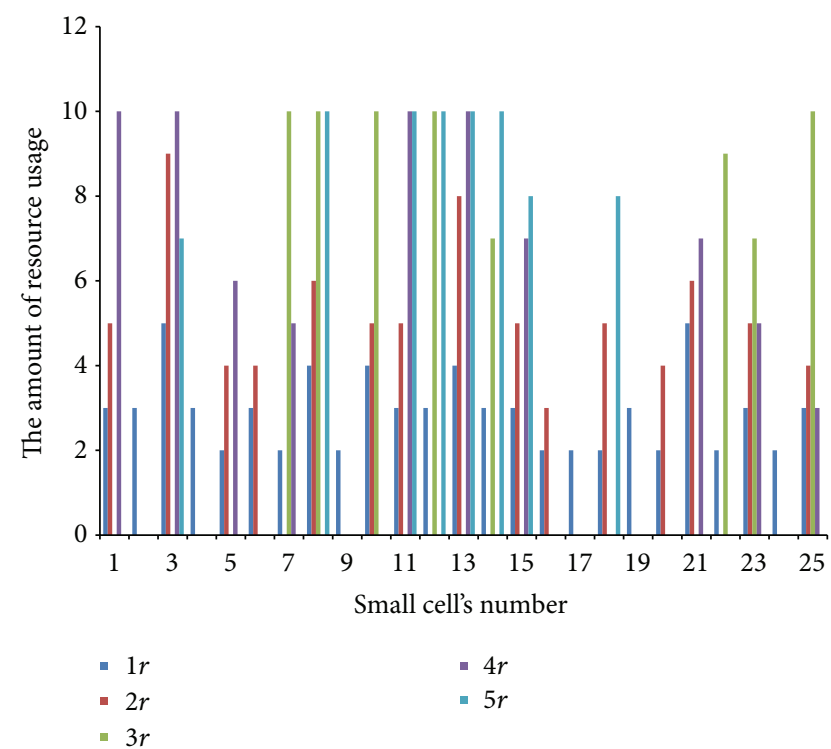

FIgURE 8: The wireless resource usage of each small cell (under discrete uniform distribution).

density can be achieved by varying the coverage radius of the small cell. "Original" indicates energy consumption when energy saving algorithm is not used, while "virtualization" indicates energy saving algorithm proposed in this paper. Along with the increase of coverage density, it can be found from Figure 7 that the energy consumption of a small cell functions is of minimum value when the number of small cells is fixed. This conclusion is consistent with the energy consumption analysis in Section 5. It indicates that there is a coverage density value making the energy consumption of the network minimum when the number of mobile terminals is certain. Using wireless virtualized network mapping algorithm can save the network energy consumption.

Figure 8 shows the wireless resource usage of each small cell. The ordinate indicates the amount of wireless resources 

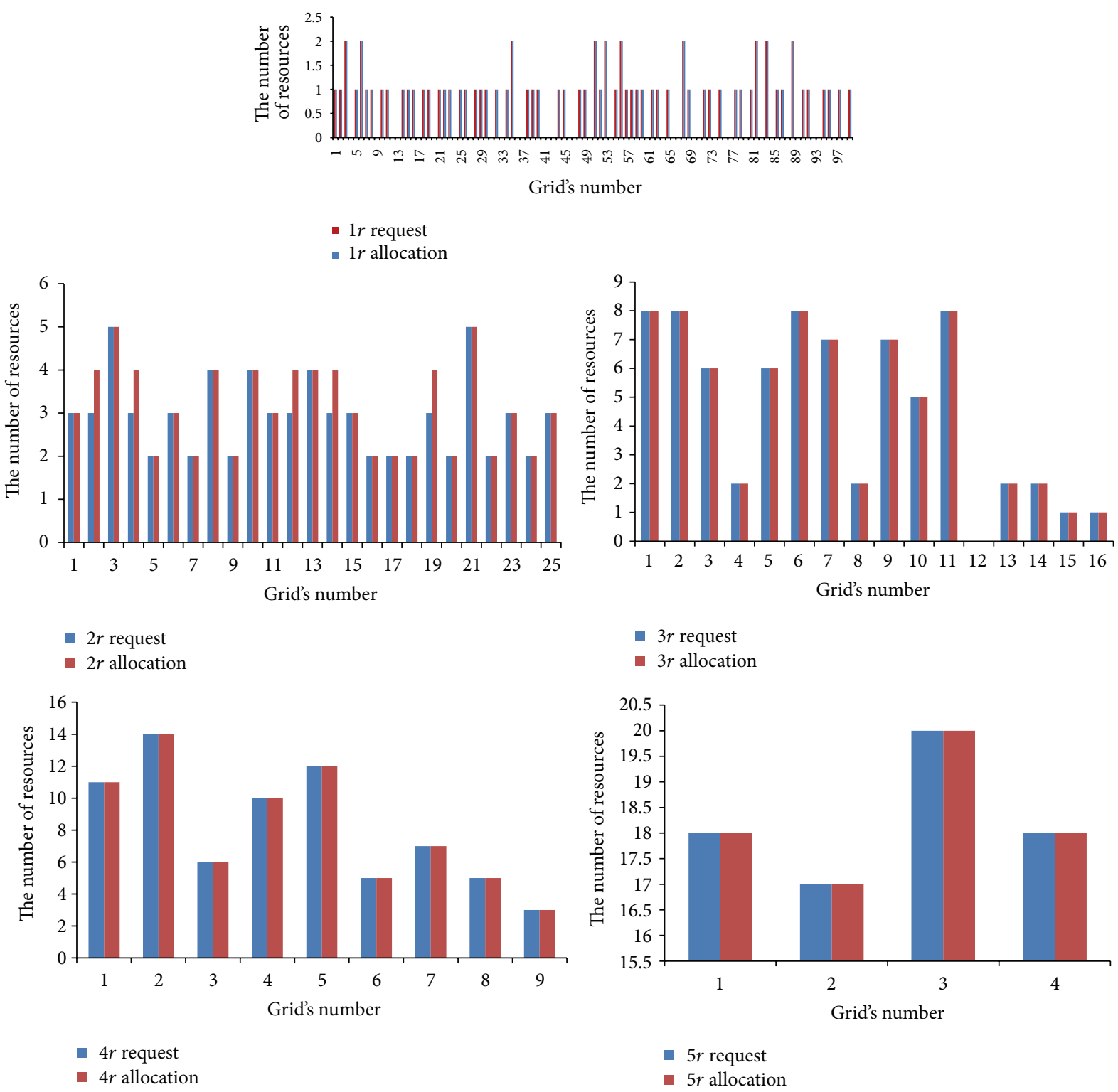

FIGURE 9: The volume of requests and the actual distribution of each grid area wireless resources (under discrete uniform distribution).

of the small cells with a maximum of 10 which means the usage rate is $100 \%$. It could be seen from Figure 8 that, with the greater coverage radius of small cells, the wireless resource usage of active small cells becomes greater and the number of the sleeping small cells becomes larger. In conjunction with Figure 7, it can be found that the coverage radius is maximum and the number of sleeping small cells is increasing, but energy consumption is not the least when " $5 r=100 \sqrt{2}$." This is mainly because the energy consumption increases with the increase of the distance when small cells receive or transmit data.

Figure 9 shows the volume of requests and the actual distribution of each grid area wireless resources with the increase of coverage radius. The virtual cell area changes, while the required allocation wireless resources have also increased, with the increase of the coverage radius of small cells. It can be seen from Figure 9 that the amount of allocated wireless resources is greater than or equal to the amount of requested wireless resources of grid area, which indicates that wireless virtualized network mapping algorithm on the basis of energy saving could ensure QoS requirements in the case of super-dense networks.

6.2. In the Case of the Poisson Distribution of Small Cells. Then we generate a mobile terminal in space by Poisson point process and then generate a small cell in space by Poisson point process, as shown in Figure 10. The circle in Figure 10 stands for the coverage range of small cells and the place without coverage is communication blind zone.

Figure 11 shows the energy consumption of small cells when their topology structure is in Poisson distribution, which is almost the same as the uniform distribution in 


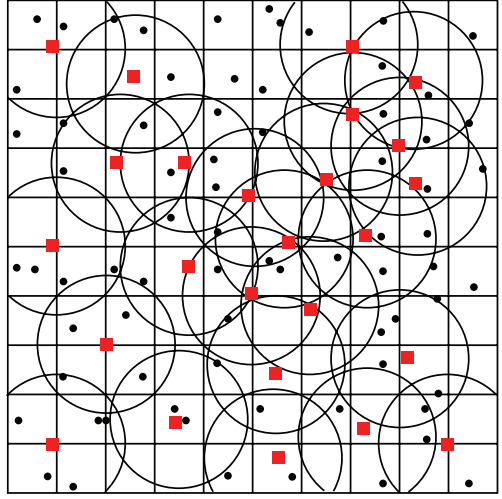

FIgURE 10: The scenario for the Poisson distribution of small cells.

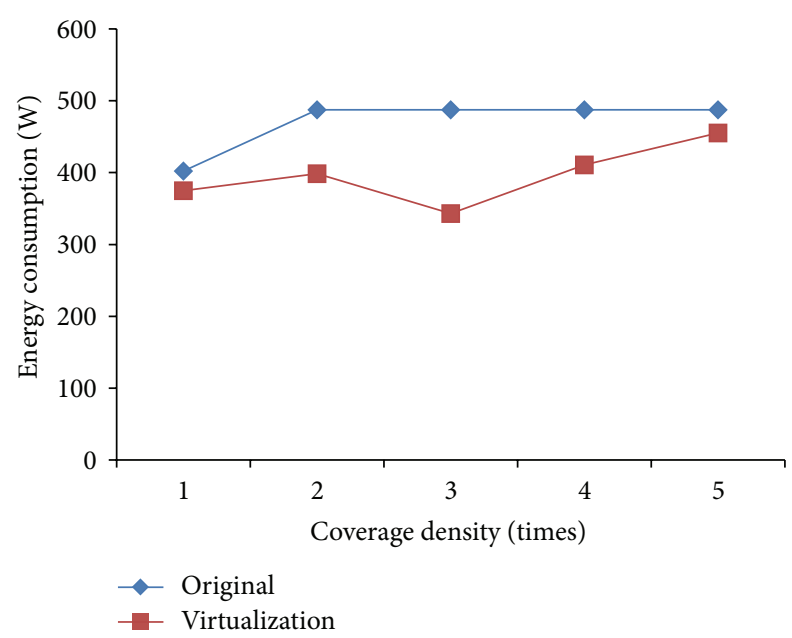

FIGURE 11: The relation of the energy consumption with the coverage density (under Poisson distribution).

Figure 7 only with the difference of energy consumption when abscissa is " $r=20 \sqrt{2}$." That is because there exists communication blind zone in Poisson distribution which makes some data fail to be transmitted.

Figure 12 is the QoS situation when algorithm is in Poisson distribution. It could be seen from Figure 12 that, from " $r=2$ " to " $r=5$," allocated wireless resources are more than or equal to the required wireless resources of grid area, satisfying the QoS. When it is " $r=1$," the required wireless resources of the 3rd grid are " 2 ," actual allocated wireless resources are "1.9," the required wireless resources of the 6th grid are " 2 ," the actual allocated wireless resources are " 0.5 ", and so on. In conjunction with Figure 10 the grid area, where QoS could not be satisfied, is communication blind zone, so the whole process of this algorithm could satisfy QoS.

6.3. Scheme of Energy Saving Analysis and Comparison. Depending on threshold value, [11] adjusts the working status of small cells. When it is lower than threshold value, small cells turn into sleeping state, which has good energy saving effects but the QoS could not be satisfied. In [14], quite a long time is needed to start relevant equipment to turn the base stations from sleeping status into working status when mobile terminal is monitored; the data packets are obviously delayed. Reference [15] is to save down-link data in buffer, and when it reaches maximum delayed range, the nodes will be woken to achieve the goal of energy saving. The energy consumption of this paper and that of [15] have been compared. " $r=3$ " is used for simulated experiment.

Figure 13 shows the situation of energy consumption while the number of mobile terminals changes. When the number of mobile terminals is between 0 and 10, the energy consumption of proposed algorithm in [15] is lower than that of TSMA. The main reason is the fact that the distance is far from small cells to mobile terminal in TSMA. When the number of mobile terminals is between 10 and 200, the energy consumption of TSMA is lower because only some of small cells are active in TSMA. When the number of mobile terminals is between 200 and 250, the energy consumption of the two is almost the same. It could be concluded that there is no delay in the TSMA algorithm, but there exists certain delay when small cells turn into working status from sleeping status when algorithm of [15] is used. When the number of mobile terminals is between 1 and 40 or between 190 and 250, TSMA's energy consumption grows linearly. When the number of mobile terminals is between 40 and 190, the energy consumption grows by leaps and bounds. That is mainly because four active small cells can process the data and the energy consumption when the number of mobile terminals is between 1 and 40. The energy consumption is mainly determined by the amount of data regardless of the number of small cells. Between 210 and 250 all the small cells are active, so it is also increasing linearly. Energy leaping growth between 40 and 190 is mainly due to the wake-up of small cells with the mobile terminal, thereby reducing the distance of data transmission, which is consistent with the theoretical analysis.

\section{Conclusion}

In this work, to save the high energy consumption of the wireless access network, we have put forward a method (a two-stage wireless virtualized network resource mapping algorithm) based on virtualization technology. Numerical results confirm the effectiveness of the scheme that can save system energy consumption on the basis of ensuring the QoS of the users. In the future, we will study the mapping algorithm based on energy conservation under the condition of heterogeneous networks and spectrum spatial reuse.

\section{Conflict of Interests}

The authors declare that there is no conflict of interests regarding the publication of this paper.

\section{Acknowledgments}

This work was supported by the National High-Tech R\&D Program of China (863 Program 2015AA01A705), Chongqing Education Science Project of China (kj1402905 


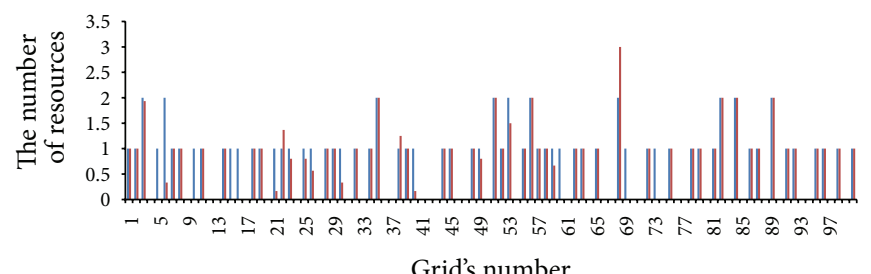

- $1 r$ request

- $1 r$ allocation
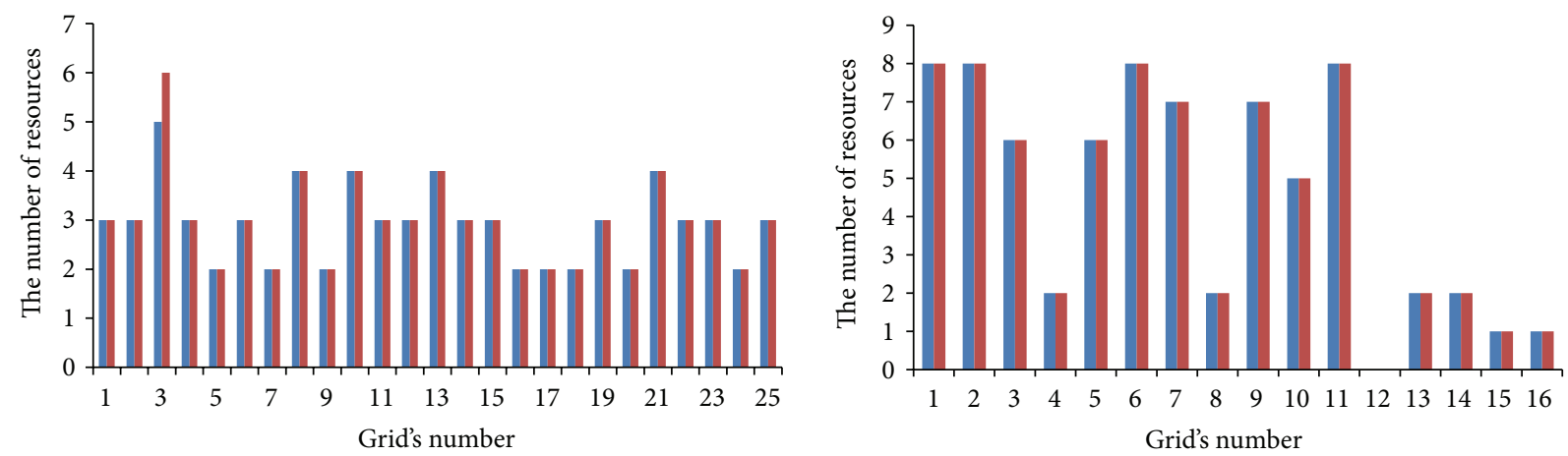

- $2 r$ request

- $2 r$ allocation

- $3 r$ request

- $3 r$ allocation
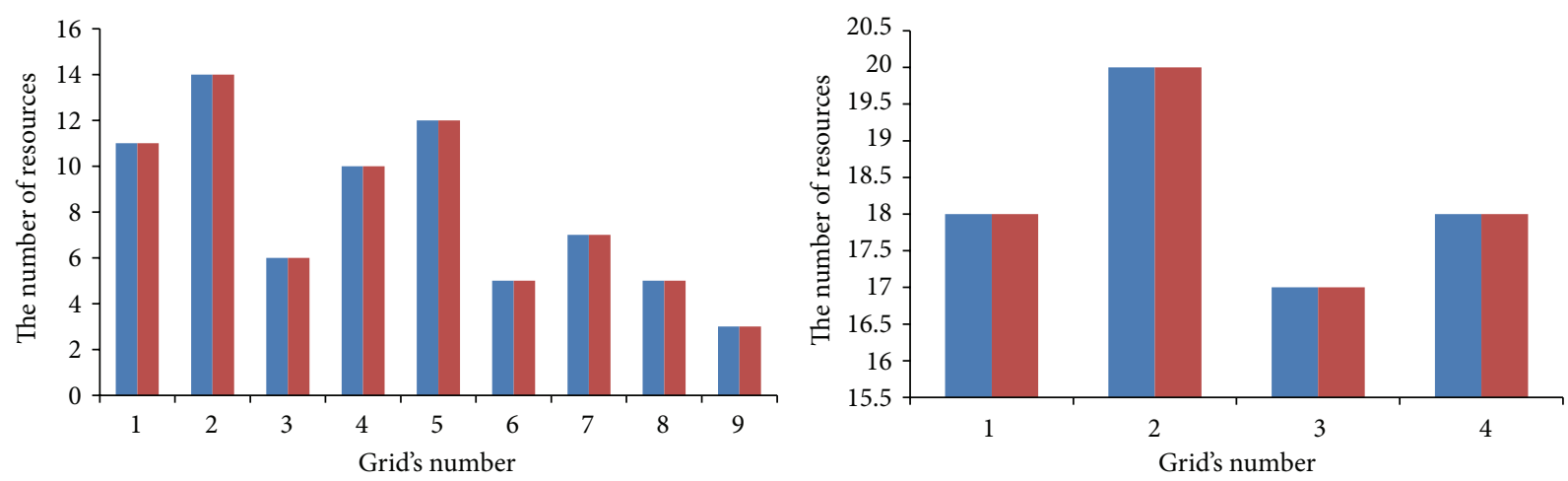

- $4 r$ request

- $4 r$ allocation

- $5 r$ request

- $5 r$ allocation

FIGURE 12: The requested amount of and actual allocated amount of wireless resources (under Poisson distribution).

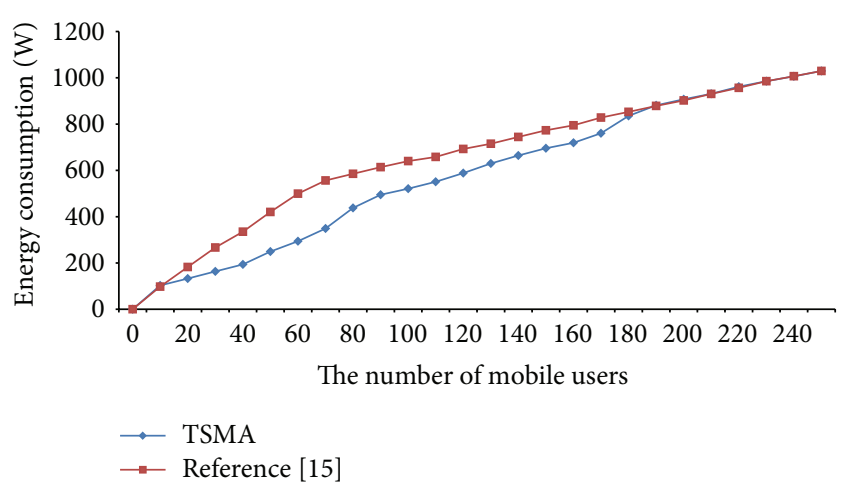

FIGURE 13: The situation of energy consumption while the number of mobile terminals changes. and kj1503011), Chongqing Twelfth Five-Year plan educational projects of China (2013-ZJ-077), and Ministry of Education and Mobile Research Fund Project of China (MCM20130661). The authors would like to show their deepest gratitude to professor Wei-hua Zhuang, University of Waterloo Canada, who has provided them with valuable guidance in the study.

\section{References}

[1] Z. Niu, X. Guo, S. Zhou, and P. R. Kumar, "Characterizing energy-delay tradeoff in hyper-cellular networks with base station sleeping control," IEEE Journal on Selected Areas in Communications, vol. 33, no. 4, pp. 641-650, 2015. 
[2] J. López-de-Armentia, D. Casado-Mansilla, S. López-Pérez, and D. López-de-Ipiña, "Reducing energy waste through eco-aware everyday things," Mobile Information Systems, vol. 10, no. 1, pp. 79-103, 2014.

[3] P. Serrano, X. Costa-Pérez, J. Wu et al., "Green communications," Computer Networks, vol. 78, pp. 1-3, 2015.

[4] I. Chih-Lin, C. Rowell, S. Han, Z. Xu, G. Li, and Z. Pan, "Toward green and soft: a $5 \mathrm{G}$ perspective," IEEE Communications Magazine, vol. 52, no. 2, pp. 66-73, 2014.

[5] M. Peng, Y. Li, Z. Zhao, and C. Wang, "System architecture and key technologies for $5 \mathrm{G}$ heterogeneous cloud radio access networks," IEEE Network, vol. 29, no. 2, pp. 6-14, 2015.

[6] J. G. Andrews, S. Buzzi, W. Choi et al., "What will 5G be?" IEEE Journal on Selected Areas in Communications, vol. 32, no. 6, pp. 1065-1082, 2014.

[7] Z. Niu, Y. Wu, J. Gong, and Z. Yang, "Cell zooming for cost-efficient green cellular networks," IEEE Communications Magazine, vol. 48, no. 11, pp. 74-79, 2010.

[8] L. Suárez, L. Nuaymi, and J.-M. Bonnin, "Energy-efficient BS switching-off and cell topology management for macro/femto environments," Computer Networks, vol. 78, pp. 182-201, 2015.

[9] B. Rengarajan, G. Rizzo, and M. A. Marsan, "Energy-optimal base station density in cellular access networks with sleep modes," Computer Networks, vol. 78, pp. 152-163, 2015.

[10] E. Oh, B. Krishnamachari, X. Liu, and Z. Niu, "Toward dynamic energy efficient operation of cellular network infrastructure," IEEE Communications Magazine, vol. 49, no. 6, pp. 56-61, 2011.

[11] R. Li, Z. Zhao, Y. Wei, X. Zhou, and H. Zhang, "GM-PAB: a grid-based energy saving scheme with predicted traffic load guidance for cellular networks," in Proceeding of the IEEE International Conference on Communications (ICC '12), pp. 1160-1164, Ottawa, Canada, June 2012.

[12] C. Liu, B. Natarajan, and H. Xia, "Small cell base station sleep strategies for energy efficiency," IEEE Transactions on Vehicular Technology, 2015.

[13] Y.-H. Choi, J. Lee, J. Back, S. Park, Y. Chung, and H. Lee, "Energy efficient operation of cellular network using on/off base stations," International Journal of Distributed Sensor Networks, vol. 2015, Article ID 108210, 7 pages, 2015.

[14] A. R. Dhaini, P.-H. Ho, G. Shen, and B. Shihada, "Energy efficiency in TDMA based next-generation passive optical access networks," IEEE/ACM Transactions on Networking, vol. 22, no. 3, pp. 850-863, 2014.

[15] L. Liu, X. Cao, Y. Cheng, and Z. Niu, "Energy-efficient sleep scheduling for delay-constrained applications over WLANs," IEEE Transactions on Vehicular Technology, vol. 63, no. 5, pp. 2048-2058, 2014.

[16] X. Chen, J. Wu, Y. Cai, H. Zhang, and T. Chen, "Energyefficiency oriented traffic offloading in wireless networks: a brief survey and a learning approach for heterogeneous cellular networks," IEEE Journal on Selected Areas in Communications, vol. 33, no. 4, pp. 627-640, 2015.

[17] Q. Han, B. Yang, C. Chen, and X. Guan, "Backhaul-aware joint user association and resource allocation for energy-constrained HetNets," http://arxiv.org/abs/1504.03503.

[18] S. Videv, J. S. Thompson, H. Haas, and P. M. Grant, "Resource allocation for energy efficient cellular systems," EURASIP Journal on Wireless Communications and Networking, vol. 2012, article 181, 2012.

[19] X. Ge, B. Yang, J. Ye, G. Mao, C. Wang, and T. Han, "Spatial spectrum and energy efficiency of random cellular networks,"
IEEE Transactions on Communications, vol. 63, no. 3, pp. 10191030, 2015.

[20] S. Luo, R. Zhang, and T. J. Lim, "Downlink and uplink energy minimization through user association and beamforming in CRAN," IEEE Transactions on Wireless Communications, vol. 14, no. 1, pp. 494-508, 2015.

[21] J. Tang, D. K. C. So, E. Alsusa, and K. A. Hamdi, "Resource efficiency: a new paradigm on energy efficiency and spectral efficiency tradeoff," IEEE Transactions on Wireless Communications, vol. 13, no. 8, pp. 4656-4669, 2014.

[22] K. Lee, P. Mitchell, and D. Grace, "Energy efficient distributed reservation multiple access with adaptive switching requests for wireless networks," IEEE Transactions on Wireless Communications, vol. 13, no. 1, pp. 259-267, 2014.

[23] F. Richter, A. J. Fehske, and G. P. Fettweis, "Energy efficiency aspects of base station deployment strategies for cellular networks," in Proceedings of the 70th IEEE Vehicular Technology Conference Fall (VTC-Fall '09), pp. 1-5, IEEE, Anchorage, Alaska, USA, September 2009.

[24] W. Nie, F.-C. Zheng, X. Wang, S. Jin, and W. Zhang, "Energy efficiency of cross-tier base station cooperation in heterogeneous cellular networks," http://arxiv.org/abs/1406.1867.

[25] S. Boiardi, A. Capone, and B. Sansó, "Radio planning of energyaware cellular networks," Computer Networks, vol. 57, no. 13, pp. 2564-2577, 2013.

[26] V. Lira, E. Tavares, S. Fernandes, and P. Maciel, "Dependable virtual network mapping," Computing, vol. 97, no. 5, pp. 459481, 2015.

[27] A. Fischer, J. F. Botero, M. T. Beck, H. De Meer, and X. Hesselbach, "Virtual network embedding: a survey," IEEE Communications Surveys \& Tutorials, vol. 15, no. 4, pp. 1888-1906, 2013.

[28] X.-H. Chen, C.-Z. Li, L.-Y. Chen, and Z.-B. Zeng, "Energy efficient virtual network embedding based on actively hibernating substrate nodes and links," Journal of Software, vol. 25, no. 7, pp. 1416-1431, 2014 (Chinese).

[29] J. F. Botero and X. Hesselbach, "Greener networking in a network virtualization environment," Computer Networks, vol. 57, no. 9, pp. 2021-2039, 2013.

[30] S. Su, Z. Zhang, X. Cheng, Y. Wang, Y. Luo, and J. Wang, "Energy-aware virtual network embedding through consolidation," in Proceedings of the IEEE Conference on Computer Communications Workshops (INFOCOM WKSHPS '12), pp. 127-132, Orlando, Fla, USA, March 2012.

[31] B. Wang, X. Chang, J. Liu, and J. K. Muppala, "Reducing power consumption in embedding virtual infrastructures," in Proceedings of the IEEE Globecom Workshops (GC Wkshps '12), pp. 714-718, IEEE, Anaheim, Calif, USA, December 2012.

[32] X. Chang, B. Wang, J. Liu, W. Wang, and J. K. Muppala, "Green cloud virtual network provisioning based ant colony optimization," in Proceeding of the 15th Annual Conference on Genetic and Evolutionary Computation (GECCO '13), pp. 15531560, Amsterdam, The Netherlands, July 2013.

[33] S. Zou, Y. Zhang, and Y. Tang, "Resource allocation mechanism based on two-step mapping for saving energy in wireless network virtualization," in Proceedings of the International Conference on Anti-Counterfeiting, Security and Identification (ASID '15), pp. 150-154, Xiamen, China, September 2015.

[34] Y. Zou and K. Chakrabarty, "A distributed coverage- and connectivity-centric technique for selecting active nodes in wireless sensor networks," IEEE Transactions on Computers, vol. 54, no. 8, pp. 978-991, 2005. 
[35] S. Zou, Y. Xu, F. Zou, X. Jiang, H. Deng, and Y. Yu, "A distributed approximate algorithm for minimal connected cover set problem in sensor networks," in Proceedings of the WRI International Conference on Communications and Mobile Computing (CMC '09), pp. 556-562, Yunnan, China, January 2009.

[36] W. Xiaoyi, Based on the key technologies of LTE system level simulation research [Ph.D. thesis], Beijing University of Posts and Telecommunications, Beijing, China, 2010.

[37] Vienna LTE-A simulator, http://www.nt.tuwien.ac.at/research/ mobile-communications/vienna-lte-a-simulators/.

[38] S. Morosi, P. Piunti, and E. Del Re, "Sleep mode management in cellular networks: a traffic based technique enabling energy saving," Transactions on Emerging Telecommunications Technologies, vol. 24, no. 3, pp. 331-341, 2013.

[39] O. Arnold, F. Richter, G. Fettweis, and O. Blume, "Power consumption modeling of different base station types in heterogeneous cellular networks," in Proceedings of the Future Network and Mobile Summit, pp. 1-8, IEEE, Florence, Italy, June 2010. 

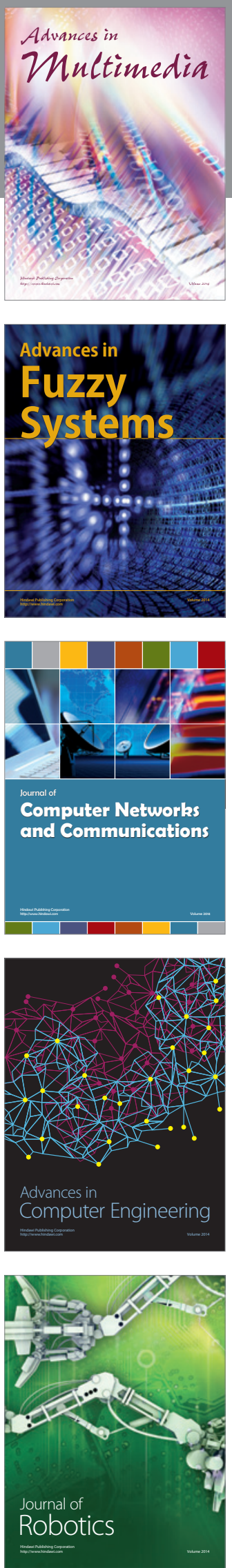

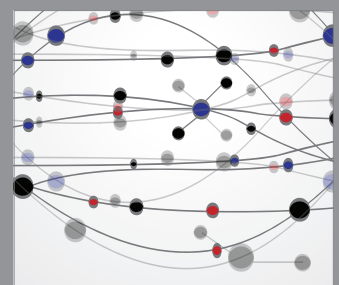

The Scientific World Journal
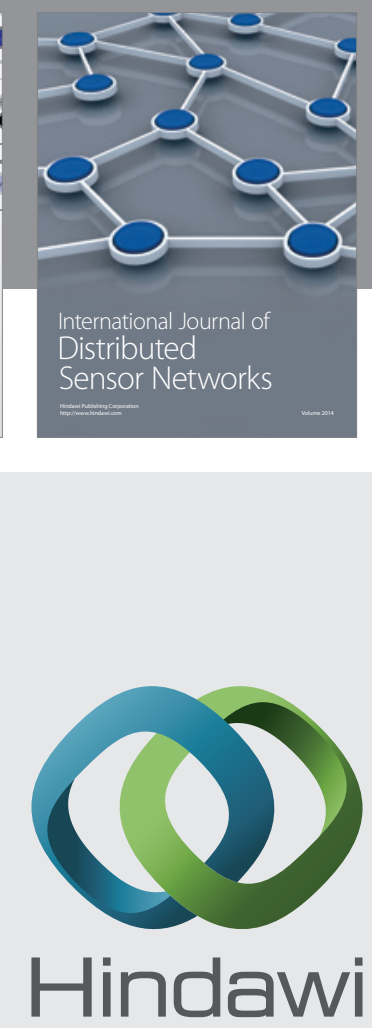

Submit your manuscripts at

http://www.hindawi.com
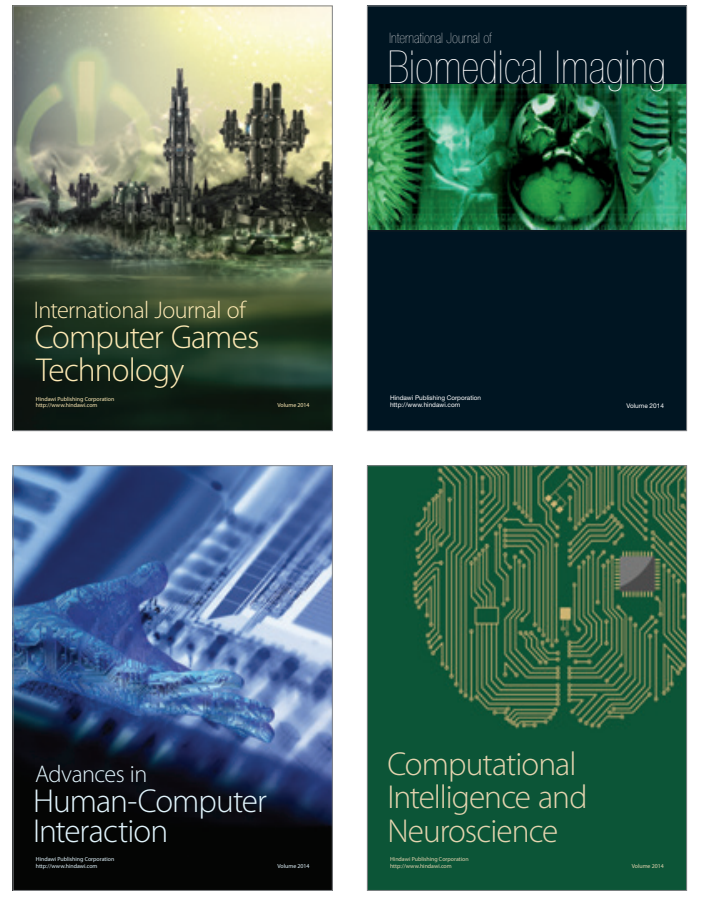
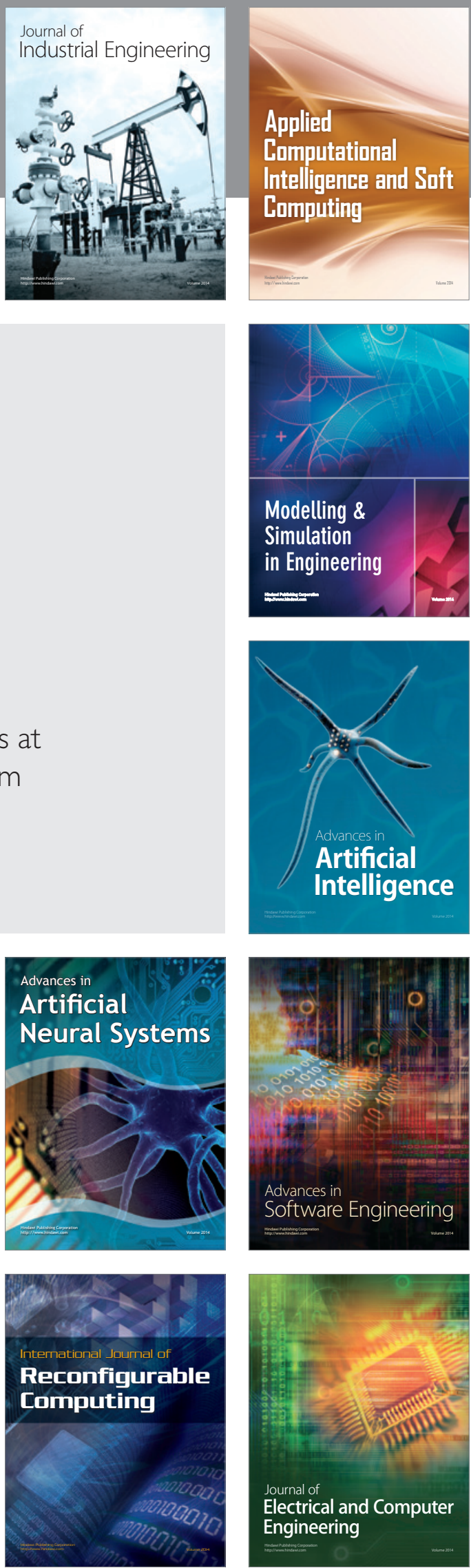